\title{
ON THE ASYMPTOTIC BEHAVIOURS OF SOLUTIONS OF THIRD ORDER NON-LINEAR AUTONOMOUS DIFFERENTIAL EQUATION GOVERNING THE MHD FLOW
}

\author{
B. B. Singh AND I. M. CHANDARKI
}

Abstract. This paper deals with the asymptotic behaviour as $t \rightarrow \infty$ of the solutions for a steady laminar incompressible boundary layer equations governing the MHD flow near the forward stagnation point of two-dimensional and axisymmetric bodies. The asymptotic behaviour of the solutions is based on the method of asymptotic integration of second order linear differential equations. The results pertaining to the asymptotic behaviour of the solutions are also expressed in the form of Theorems 4.1 and 4.2 .

Mathematics subject classification (2010): 76Bxx, 76W05, 35B40, 76D10.

Keywords and phrases: boundary layers, MHD, asymptotic integration.

\section{REFERENCES}

[1] E. H. Aly, L. Elliot And D. B. Ingham, Mixed convection boundary layer flow over a vertical surface embedded in a porous medium, Eur. J. Mech. B Fluids, 22 (2003), 529-543.

[2] M. AmKadNi, A. AzZouzI AND Z. Hammouch, On the exact solutions of laminar MHD flow over a stretching flat plate, Commun. Nonlinear Sci. Numer. Simul., 13, 2 (2008), 359-368.

[3] Z. Belhachmi, B. BRighi And K. TaOus, On the concave solutions of the Blasius equation, Acta Math. Univ. Comenian, 69, 2 (2000), 199-214.

[4] H. Blasius, Grenzchichten in Flussigkeiten mit Kleiner Reibung, Z. Math. Phys., 56 (1908), 1-37.

[5] B. BRIGHI AND J. D. HoERneL, On similarity solutions for boundary layer flows with prescribed heat flux, Math. Methods Appl. Sci., 28, 4 (2005), 479-503.

[6] B. BRIGHI AND J. D. HOERNEL, On the concave and convex solutions of a mixed convection boundary layer approximation in a porous medium, Appl. Math. Lett., 19 (2006), 69-74.

[7] B. BRIGHI AND J. D. HOERNEL, Recent advances on similarity solutions arising during free convection, Elliptic and parabolic problems, 83-92, Progr. Nonlinear Differential Equations Appl., 63, Birkhäuser, Basel, 2005.

[8] L. CESARI, Asymptotic behavior and stability problems in ordinary differential equations, Academic Press Inc., Publishers, New York; Springer-Verlag, Berlin-Göttingen-Heidelberg 1963.

[9] A. CHAKRABARTI AND A. S. GUPTA, Hydromagnetic flow and heat transfer over a stretching sheet, Q. appl. Math., 37 (1979), pp. 73-78.

[10] Lu Chinquing, A. D. Mac Gillivray and S. P. Hastings, Asymptotic behaviour of solutions of a similarity equation for laminar flows in channels with porous walls, IMA J. Appl. Math., 49, 2 (1992), 139-162.

[11] W. A. Coppel, On a differential equation of boundary layer theory, Philos. Trans. Roy. Soc. London. Ser. A, 253 (1960), 101-136.

[12] V. M. Falkner AND S. W. Skan, Some approximations of the boundary layer equations, Philos. Mag., 12 (1931), 865-896.

[13] J. J. Gergen And F. G. Dressel, Second order linear and nonlinear differential equations, Proc. Amer. Math. Soc., 16 (1965), 767-773.

[14] D. Grohne AND R. IGLISCH, Die laminare Grenzschcht an der langsanges trompten ebenum Platte mit schragem Absaugen and Ausblasen, Veroffentlichung des Mathematischen Institutes der Technischen Hochschule Braunschweig, Bericht, 45, 1 (1945). 
[15] M. GuEDDA, Multiple solutions of mixed convection boundary-layer approximations in a porous medium, Appl. Math. Lett., 19, 1 (2006), 63-68.

[16] M. Guedda AND Z. Hammouch, On similarity and pseudo-similarity solutions of Falkner-Skan boundary layers, Fluid Dynam. Res., 38, 4 (2006), 211-223.

[17] W. A. HARRIS, P. PUCCI AND J. SERRIN, Asymptotic behavior of solutions of a nonstandard second order differential equation, Differential Integral Equations, 6, 6 (1993), 1201-1215.

[18] P. HARTMAN, On the asymptotic behavior of solutions of a differential equation in boundary layer theory, Z. Angew. Math. Mech., 44 (1964), 123-128.

[19] P. HaRTMan, Ordinary Differential Equations, John Wiley \& Sons, Inc. New York-London-Sydney, 1964.

[20] R. T. Herbst, The equivalence of linear and nonlinear differential equations, Proc. Amer. Math. Soc., 7 (1956), 95-97.

[21] R. IGLisCh AND F. Kemnitz, Uber die in der grenschichttheorie auftretende differential glechung $f^{\prime \prime \prime}+f f^{\prime \prime}+\beta\left(1-f^{\prime 2}\right)=0$ fur $\beta<0$ beigewissen absaugl and ausblasegesetzen, 50 Jahre Grenz schichtforstung, Festschrift, 1955.

[22] E. KAмKe, Zur Theorie der Systeme gewöhnlicher Differentialgleichungen, Acta Math., 58, 1 (1932), $57-85$.

[23] J. D. KeckiC AND V. LJ. Kocic, Second order nonlinear differential equations equivalent to linear differential equations, Publ. Inst. Math. (Beograd) (N.S.), 24, 38 (1978), 99-101.

[24] V. LJ. Kocic, Linearization of nonlinear differential equations: third order nonlinear ordinary differential equations equivalent to linear second order equations, Publ. Inst. Math. (Beograd) (N.S.), 31, 45 (1982), 87-91.

[25] A. KumAR AND B. B. Singh, Some aspects related to the asymptotic solutions of the laminar boundary-layer equations with heat flux, Astrophys. Space Sci., 165, 1 (1990), 41-49.

[26] M. Kumari, H. S. TAKHAR AND G. NATH, Mixed convection flow over a vertical wedge embedded in a highly porous medium, Heat and Mass Transfer, 37 (2001), 139-146.

[27] P. S. LAWRENCE AND B. N. RAO, Effect of pressure gradient on MHD boundary layer over a flat plate, Acta Mech., 113 (1995), 1-7.

[28] T. R. Mahapatra AND A. S. Gupta, Magnetohydrodynamic stagnation-point flow towards a stretching sheet, Acta Mech., 152 (2001), 191-196.

[29] N. PARHI AND P. DASS, Oscillatory and asymptotic behaviour of a class of nonlinear functionaldifferential equations of third order, Bull. Calcutta Math. Soc., 86, 3 (1994), 253-266.

[30] I. Pop, M. Kumari AND G. NATH, Conjugate MHD flow past a flat plate, Acta Mech., 106 (1994), 215-220.

[31] I. PoP AND T. Y. NA, A note on MHD flow over a stretching permeable surface, Mech. Res. Commun., 25, 3 (1998) 263-269.

[32] J. SERRIN, Asymptotic behavior of velocity profiles in the Prandtl boundary layer theory, Proc. Roy. Soc. Ser. A, 299 (1967), 491-507.

[33] J. A. Shercliff, A Textbook of Magnetohydrodynamics, Pergamon Press, 1965.

[34] B. B. Singh AND A. KUMAR, Asymptotic behaviours of the solutions of MFD boundary layer flow on a moving continuous flat surface, Hunan Daxue Xuebao, 16, 1 (1989), 12-16.

[35] B. B. SINGH AND A. K. SINGH, Asymptotic behaviour, existence and uniqueness of the solutions of boundary layer flow equations at a three-dimensional stagnation point with strong blowing, Indian J. Techno., 26 (1988), 27-31.

[36] B. B. SINGH AND J. SINGH, Asymptotic behaviours of hydromagnetic boundary layer flows past a semi-infinite flat plate, Tamkang J. Math., 19, 3 (1988), 35-40.

[37] B. B. SINGH AND J. SINGH, On the asymptotic behaviour of similar profiles (II), Indian J. Theor. Phys., 36 (1988), 127-131.

[38] B. B. Singh AND J. Singh, On the asymptotic behaviours of flows near a stagnation point on a general curved surface, Indian J. Theor. Phys., 36 (1988), 25-31.

[39] B. B. Singh AND J. Singh, On the asymptotic behaviour of the solutions of the equations of the flows near saddle point of attachment, Proc. Nat. Acad. Sci. India Sect. A, 58, 4 (1988), 525-531.

[40] B. B. Singh AND S. K. Verma, Asymptotic behaviour of the laminar boundary layer flow of an incompressible fluid past a flat plate, Indian J. Engrg. Materials Sci., 61 (1999), 346-348.

[41] B. B. SINGH, Asymptotic behaviour and uniqueness of solutions of the boundary layer equations in an incompressible flow, J. Sci. Res. (BHU), 37 (1987), 37-44. 
[42] B. B. Singh, Asymptotic behaviour of similar profiles, Indian J. Pure Appl. Math., 17 (1986), 10671072 .

[43] H. S. TAKHAR, M. A. Ali AND A. S. GUPTA, Stability of magnetohydrodynamic flow over a stretching sheet, Liquid Metal Hydrodynamics (Lielpeteris \& Moreau ed.), Kluwer Academic Publishers, Dordrecht, 1989, 465-471.

[44] H. S. TAKHAR, A. A. RAPTIS AND A. A. PERDikis, MHD asymmetric flow past a semi-infinite moving plate, Acta Mech., 65 (1987), 278-290.

[45] A. TIRYAKI AND S. YAMAN, Asymptotic behaviour of a class of nonlinear functional differential equations of third order, Appl. Math. Lett., 14, 3 (2001), 327-332.

[46] W. R. UTZ, Existence of solutions of a generalized Blasius equation, J. Math. Anal. Appl., 66, 1 (1978), 55-59.

[47] Y. K. WU, Magnetohydrodynamic boundary layer control with suction or injection, J. Appl. Phys., 44 (1973), 2166-2171.

[48] K. VAJRAVELU AND D. Rollins, Hydromagnetic flow of a viscous fluid in an oscillating channel, J. Math. Phys. Sci., 31, 1 (1997), 11-24. 